\title{
Philosophiques
}

\section{Note de la rédaction}

Volume 12, numéro 1, printemps 1985

URI : https://id.erudit.org/iderudit/203273ar

DOI : https://doi.org/10.7202/203273ar

Aller au sommaire du numéro

Éditeur(s)

Société de philosophie du Québec

ISSN

0316-2923 (imprimé)

1492-1391 (numérique)

Découvrir la revue

Citer cet article

(1985). Note de la rédaction. Philosophiques, 12(1), 105-105.

https://doi.org/10.7202/203273ar

Ce document est protégé par la loi sur le droit d'auteur. L'utilisation des services d'Érudit (y compris la reproduction) est assujettie à sa politique d'utilisation que vous pouvez consulter en ligne.

https://apropos.erudit.org/fr/usagers/politique-dutilisation/
Cet article est diffusé et préservé par Érudit.

Érudit est un consortium interuniversitaire sans but lucratif composé de l’Université de Montréal, l'Université Laval et l'Université du Québec à Montréal. Il a pour mission la promotion et la valorisation de la recherche. https://www.erudit.org/fr/ 


\title{
ASPECTS PHILOSOPHIQUES DU FÉMINISME
}

\author{
NOTE DE LA RÉDACTION
}

Que des philosophes écrivent sur le féminisme, il n'y a rien là que de très normal. Tout peut servir d'amorce à une réflexion philosophique, et on ne voit pas pourquoi l'un des plus importants mouvements de civilisation du $20^{\mathrm{e}}$ siècle ferait exception. Mais qu'une série de textes sur le féminisme soit produite exclusivement par des femmes philosophes, voilà qui revêt une importance particulière et témoigne des acquis du mouvement en question, même si son travail est loin d'être terminé.

La direction de Philosophiques est fière de présenter à ses lecteurs une telle série de textes, dont le contenu et l'optique sont fort variés : discours féministes, critiques de discours féministes et critiques de discours anti-féministes s'y cotoient. Ces textes sont pour la plupart des versions modifiées de communications présentées lors de divers colloques et congrès tenus au Québec au cours des deux ou trois dernières années, et ils ont été retenus pour publication conformément à notre procédé habituel de sélection des textes. Aucun d'eux n'a été composé en vue de la présente publication, et ils ne constituent donc pas un ensemble organique. Mais ils préser.tent un intéressant éventail de points de vue sur le féminisme. La diversité d'écritures et d'orientations idéologiques qu'on y trouve reflète, bien sûr, les tensions internes du mouvement féministe, mais aussi sa richesse et sa vitalité. 